\title{
Interpretações sobre 0 Japão mediadas pelo reality show Ainori Love Van
} Japan's interpretations mediated by the reality Ainori Love Van

Mayara Araujo ${ }^{1}$

Krystal Urbano²

\footnotetext{
${ }^{1}$ Doutoranda do Programa de Pós-graduação Comunicação da Universidade Federal Fluminense (PPGCOM-UFF). Mestre em Comunicação e Cultura pela Universidade do Estado do Rio de Janeiro. Contato: msoareslpa@yahoo.com.br

${ }^{2}$ Doutora e Mestre pelo Programa de Pós-Graduação em Comunicação da Universidade Federal Fluminense (PPGCOM-UFF). Contato: krystal.cortez@gmail.com
} 
Resumo: O artigo discute a instrumentalização do soft power japonês através dos discursos veiculados sobre o Japão e seu relacionamento com os países vizinhos encontrados no reality show Ainori Love Van: Asian Journey (2017-2019), disponível na Netflix. Para tanto, damos enfoque ao caso de Taiwan, um dos destinos turísticos visitados pelos participantes da primeira temporada do referido programa. Os resultados da pesquisa apontam que o programa tenta desconstruir a memória negativa associada ao imperialismo japonês, iniciado no século XX, na medida em que reforça a ideia amplamente difundida de que o Japão é cool.

Palavras-chave: reality shows; imperialismo; soft power; Taiwan; Japão.

Abstract: This article discusses the instrumentalization of Japanese soft power through the discourses broadcast about Japan and its relationship with neighboring countries in the reality show Ainori Love Van: Asian Journey (2017-2019) available on Netflix. For such, we focus on the case of Taiwan, one of the tourist destinations visited by participants in the first season. The research results show that the program tries to deconstruct the negative memory associated with Japanese imperialism, which started in the 20th century, as it reinforces the widely held idea that Japan is cool.

Keywords: reality shows; imperialism; soft power; Taiwan; Japan. 


\section{Introdução}

Normalmente associado a uma gama de produtos midiáticos referentes à sua cultura pop, como Hello Kitty, Dragon Ball e Pokémon, o imaginário sobre o Japão nem sempre teve uma faceta tão cool ou descolada. A presença japonesa no continente asiático possui um passado sombrio, vinculado a exploração e colonização dos países vizinhos, além de ter praticado um imperialismo que se apresentava aos moldes ocidentais, o que causa um profundo desconforto no entorno regional até a atualidade. Situado no Extremo Oriente, com um passado de isolacionismo para, então, ser forçado a abrir os portos e dialogar com o Ocidente, o posicionamento do Japão em um cenário global se fez complicado. Ainda que o arquipélago possua alguns traços culturais semelhantes com os demais países do Leste e Sudeste Asiático, nem sempre suas abordagens se manifestaram a favor dessa identidade “asiática” (IWABUCHI, 2002), uma vez que até pouco tempo atrás falar sobre a Ásia implicava na ideia de uma civilização distante e atrasada ao ser comparada à Europa Ocidental ou aos Estados Unidos. Esse fator colaborou para que o Japão adotasse narrativas que ora buscavam se afastar do oriente ao defender seus traços ocidentais e, posteriormente, com a ascensão dos tigres asiáticos, visassem uma aproximação com essa mesma Ásia, abraçando e incorporando seus valores (IWABUCHI, 2002).

No entanto, nos últimos decênios, a influência cultural japonesa representada pela popularização de sua cultura pop (ALBUQUERQUE \& CORTEZ, 2015) tem atingido bons resultados em países do Leste e Sudeste Asiático, bem como em outras regiões. A fim de citar alguns exemplos, em Taiwan os cidadãos têm gradativamente buscado o Japão como destino turístico, e o lucro da marca japonesa Sanrio, responsável por personagens icônicos da indústria do entretenimento nipônica como a própria Hello Kitty e Aggretsuko, atingiu 580 milhões de dólares somente em 2016. No caso da Malásia, os eventos de animể têm conquistado públicos cada vez mais expressivos nos últimos anos (YAMATO, 2016); países como Tailândia, Coreia do Sul e Indonésia têm os seus mercados de histórias em quadrinhos completamente dominados pelos mangás (OTMAZGIN, 2007) e os dramas de TV japoneses conquistaram a juventude asiática a partir da década de 1990 (IWABUCHI, 2004). Ademais, a indústria televisiva japonesa, ainda em 2015, iniciou uma parceria com a

\footnotetext{
${ }^{3}$ Convenções realizadas por fãs de animês (desenhos animados japoneses) em diversos países do mundo. No Brasil, essas convenções são realizadas desde a década de 1990, como reflexo da popularidade e presença dos animês nas emissoras televisivas locais e, em certa medida, da diáspora japonesa ocorrida em nosso país início do século XX.
} 
plataforma de streaming Netflix, o que viabilizou a produção de conteúdos originais e expansão de sua produção audiovisual de maneira licenciada no mercado global. Assim, além da inserção de dramas de TV originais e uma gama considerável de animações, a parceria também acarretou a produção de reality e talk shows dos mais variados formatos e temáticas, o que vem contribuindo com a veiculação de novos discursos e imagens sobre o Japão para o restante do globo.

Com isso em vista, o artigo discute a instrumentalização do soft power japonês através do caso do reality show Ainori Love Van: Asian Journey (2017-2019), disponível no catálogo da Netflix. A partir de uma análise ancorada na primeira temporada do programa, objetivamos compreender quais são as imagens e discursos veiculados sobre o Japão e seu relacionamento com os países vizinhos no contexto contemporâneo. Embora Ainori tenha seu enfoque na procura pelo amor enquanto apresenta destinos turísticos, o reality também traz quadros didáticos sobre a história e a cultura dos países visitados, tornando o seu caráter turístico ainda mais embasado. Nesse sentido, acreditamos que os participantes - e os espectadores - acabam sendo convidados a (re)descobrir o Japão a partir da comparação e do diálogo com os outros países asiáticos representados no programa. Dito isso, partimos do pressuposto de que a edição do programa se esforça em desconstruir a memória negativa vinculada ao Japão, dado o seu passado imperialista, enquanto reforça as qualidades do soft power japonês junto aos públicos regionais e globais.

$\mathrm{O}$ argumento do texto se desenvolve em três seções. Inicialmente discutimos sobre a presença e influência cultural japonesa no continente asiático, em uma linha temporal que se inicia no período que precede a entrada do Japão na Segunda Guerra Mundial e termina nos primeiros anos do século XXI. Já na segunda seção, apresentamos as bases pelas quais o reality show Ainori Love Van foi concebido e desenvolvido pela indústria televisiva japonesa até o momento de sua transposição para a plataforma de streaming da Netflix. Por fim, num terceiro momento, analisamos os discursos e imagens veiculados sobre o Japão em Ainori Love Van: Asian Journey, dando enfoque ao relacionamento controverso estabelecido entre Japão e Taiwan, um dos destinos visitados pelos participantes do programa na referida edição.

\section{Do projeto imperialista japonês ao discurso do Cool Japan}

Até o início da Segunda Guerra Mundial, o chamado "Império Japonês" atuava como o principal poder regional no Leste Asiático. Esse poderio se estabeleceu a partir da Revolução Meiji (1867 - 1912), período em que ocorreu uma forçada aproximação entre o Japão e os países ocidentais. Nesse momento, houve uma intensa 
euforia na absorção de ideias, conteúdos e valores oriundos dessa região, mas algum tempo depois acabou acarretando a criação de um projeto político conservador de fundo nacionalista (ORTIZ, 2000). Também é a partir desse momento que o Japão se industrializa e inicia o seu processo de desenvolvimento aos moldes europeus, passando a ser reconhecido no cenário político internacional pelas grandes potências europeias da época. Embora desfrutasse de um quadro privilegiado, o arquipélago não conseguiu ser visto como uma potência semelhante ao Ocidente e, para se proteger da ameaça de colonização, o Japão se envolveu em diversas guerras a fim de expandir o seu território geográfico e garantir a sua independência (MATSUDA, 2016).

O imperialismo é uma forma de determinada nação controlar a outra, seja através da aquisição direta de território ou por meios informais, através do domínio econômico, ameaça militar ou política (HUFFMAN, 2010). No caso japonês, seu imperialismo pode ser caracterizado como uma estratégia reativa e defensiva: ao mesmo tempo em que criticava o avanço ocidental na Ásia, utilizava-se dessa mesma política para justificar o seu próprio expansionismo e exploração dos países vizinhos (SUZUKI, 2003). Por conta da rápida industrialização e intensos movimentos de demonstração de força que obtiveram sucesso, o Japão desenvolveu um senso de superioridade perante seu entorno regional. Além disso, o arquipélago forçosamente implementou políticas de modernização da Ásia, tentou banir a influência ocidental no intuito de "salvar a Ásia" e substituí-la pelo modelo japonês. Decerto, no processo de expansionismo nipônico, a “Ásia” e o “Japão” se tornaram duas entidades separadas para que pudesse se ressaltar o discurso de superioridade japonesa (IWABUCHI, 2002).

Esse Imperialismo teve suas bases sedimentadas ainda em 1895, quando o Japão incorpora a ilha de Taiwan ao seu território, a partir da vitória na primeira guerra sino-japonesa (1894-1895). Logo em seguida, entre 1904 e 1905, o Japão confirmou o seu status de potência militar ao ser bem-sucedido em uma guerra contra a Rússia, para, então, a partir da década de 1930 adotar uma explícita postura imperialista contra os seus vizinhos asiáticos. Sendo assim, é difícil precisar a extensão do alcance japonês através da "Esfera de co-prosperidade do grande Leste Asiático", nomenclatura que foi desenvolvida no intuito de justificar o caráter imperialista e agressivo do Japão diante dos demais países da região. De acordo com Otmazgin (2012), esse espaço de "co-properidade" compreendia o Japão, a Coreia, Manchúria e algumas partes do sudeste asiático. Huffman (2010) acrescenta nessa área regiões como a Malásia, Filipinas, Indonésia, Burma e outras ilhas do pacífico, no período que precede a entrada do Japão na segunda guerra. 
O fato é que o termo se refere a uma iniciativa que objetivava "libertar a região do domínio ocidental" (HUFFMAN, 2010; OTMAZGIN, 2012) através do apoio ao Japão a partir da utilização de recursos e mão-de-obra das colônias como prova de lealdade. Embora a influência japonesa não se desse de forma homogênea, os países englobados sofreram as consequências desses movimentos imperialistas para além do escopo da invasão territorial. Assim, países como a Malásia e a Indonésia, por exemplo, viviam sob supervisão militar japonesa a partir de 1940, enquanto a Tailândia permaneceu independente sob um acordo que permitia que o Japão utilizasse o país como base para suas tropas e que viabilizou a construção de campos de prisioneiros, especificamente entre 1941 e 1945, durante a guerra do pacífico. (HUFFMAN, 2010, p. 61).

Ainda nas décadas que antecedem a entrada do arquipélago na segunda guerra mundial, o Japão se apropriou da narrativa de ideais universais entre os países asiáticos e da lógica da cooperação mútua, em prol do desenvolvimento. No entanto, talvez a característica mais evidente desses esforços diz respeito a ideia de uma suposta superioridade racial e cultural japonesa, que implicava em inferiorizar os países vizinhos e garantia o papel central do Japão em seu projeto imperialista. Para tanto, o imperialismo e a colonização japonesa ocorreram de forma tão brutal que, além do uso da força e agressão, também obrigava as colônias a adotarem elementos de sua cultura, como a proibição do idioma nacional em Taiwan e na Coreia. Essas experiências chegaram ao ponto de obrigar os povos coreanos e taiwaneses a trocarem seus nomes originais por nomes japoneses (JOO, 2011; OTMAZGIN, 2012) e a forçarem a substituição de calendários para que se adequassem a numeração japonesa. Intelectuais e artistas foram enviados para as colônias no intuito de convencer a população nativa da superioridade japonesa (OTMAZGIN, 2012). Objetivava-se, portanto, a erradicação das culturas locais e substituição pela "superior” cultura japonesa.

Esse imperialismo foi freado por conta da derrota do Japão na Segunda Guerra mundial, o que tornou esse término particular. Nas experiências imperialistas europeias, o término do expansionismo ocorre de maneira orgânica, seja por parte das colônias ou dos colonizadores. No caso japonês, a derrota na guerra implicou no "abandono" de suas colônias, uma vez que simplesmente não existia a possibilidade do projeto de o Império Japonês continuar (HUFFMAN, 2010). Com isso, a geopolítica que passou a reger o leste e o sudeste asiático foi consequência do momento da guerra fria, na qual os Estados Unidos substituíram o Japão, ao passar a assumir o controle dos mares da Ásia e a regular a segurança econômica e militar da região (HUNG, 2018). 
De 1945 a meados da década de 1970, o governo japonês realizou pouquíssimos esforços para promover sua cultura na Ásia, receoso de causar reações negativas devido à vívida memória do imperialismo na região. Em paralelo, alguns governos da região - como o de Taiwan - proibiram a importação da cultura japonesa devido a essas considerações históricas e políticas (OTMAZGIN, 2012). Não obstante, as exportações culturais não haviam sido diagnosticadas como um setor de sucesso para contribuir com a economia japonesa. Otmazgin (2012) ainda ressalta que o imperialismo cultural não fez parte dos objetivos de Estado naquele momento. A cultura foi vista como um possível empecilho para as negociações da compra de recursos necessários para a economia japonesa. Isso se contrasta com o forte investimento do governo japonês na criação de produtos manufaturados, como eletrônicos e automóveis. Por outro lado, a saída dos Estados Unidos do território japonês em 1952 permitiu que o governo investisse diretamente na promoção cultural para o mercado doméstico (OTMAZGIN, 2012). Os esforços, nesse caso, foram de incentivar as práticas culturais "tradicionais" - como preservar monumentos históricos, prática de ikebana (arranjos florais) e de shodo (caligrafia) - da cultura japonesa e que continuaram a desenvolver uma noção de superioridade nipônica, através de um discurso essencialista sobre a excepcionalidade japonesa que reverberam até a atualidade.

Foi somente a partir de meados dos anos 1970, durante o governo do Primeiro Ministro Takeo Fukada (1976 - 1978), que a cultura voltou a ser um tópico relevante para as relações diplomáticas entre o Japão e o sudeste asiático. Durante o seu mandato, era objetivo do Japão buscar o "intercâmbio cultural” com os outros países do entorno regional e Fukada fazia questão de enfatizar que não fazia parte dos interesses japoneses se tornar um novo império cultural e militar. Concomitantemente, a década de 1970 é marcada pelo "milagre econômico japonês", que veio a se tornar a segunda maior economia do mundo na década posterior. Assim, o discurso de Fukada falava sobre uma "cooperação cultural" ou "intercâmbio cultural", palavras escolhidas por se referirem a uma retórica mais branda e que buscavam amenizar possíveis temores sobre o sucesso econômico do Japão (OTMAZGIN, 2012; IWABUCHI, 2015). No entanto, suas políticas foram alvo de sérios protestos na Tailândia e na Indonésia, lembrando ao Japão que o ressentimento sobre o imperialismo do início do século continuava presente, mesmo 30 anos após a derrota japonesa na segunda guerra (OTMAZGIN, 2012, p. 49). De fato, essa sombra do passado levou países como a Coreia do Sul a banir conteúdos japoneses desde a desocupação de seu território até 1998. No caso da 
Malásia, Tailândia e Filipinas, certos produtos da cultura pop japonesa podem ser censurados até hoje.

Em síntese, os trinta anos posteriores ao término da segunda guerra mundial foram marcados por um grande receio por parte do governo japonês em utilizar sua cultura como ferramenta diplomática em diálogo com os vizinhos asiáticos. Nesse sentido, seus investimentos enfatizaram o mercado doméstico, deixando a mercantilização e exportação de produtos culturais exclusivamente nas mãos do setor privado. Essa situação só vem a se transformar na década de 1990.

Alguns fatores ajudaram a desencadear nessa transformação na última década do século XX: a) o sucesso que o mercado privado também conquistou na exportação de produtos midiáticos (principalmente para o Ocidente) levou o governo japonês a se reposicionar e a perceber o potencial político do campo cultural (OTMAZGIN, 2012); b) o surgimento de uma grande classe média urbana em muitas partes da Ásia em diálogo com a percepção de que a cultura pop japonesa atingia a juventude asiática, a despeito das marcas do imperialismo passado (IWABUCHI, 2015; ANG, 2010). Embora parte da população asiática se ressinta até hoje dos horrores do imperialismo japonês, isso não impediu o consumo de produtos do pop japonês, como as animações e os quadrinhos - principalmente pela camada mais jovem da população que não vivenciou as experiências do imperialismo nipônico. Iwabuchi (2002) acentua o caráter "inodoro" dos animês e mangás, dada a ausência de características étnicas dos personagens e, por fim; c) a emergência de conglomerados de mídia globais no final do século XX desencadeou em uma abundância de conteúdo audiovisual em todo o mundo. Nesse mesmo período, a Ásia crescia economicamente de forma rápida, tornando-se um espaço disputado pelos conglomerados ocidentais. Isso foi um sinal de alerta para países como China, Singapura e Malásia, que reagiram contra a extensiva invasão de produções norte-americanas, em defesa de “valores asiáticos" (IWABUCHI, 2002). Ao mesmo tempo, com a ascensão dos tigres asiáticos e a crescente pujança econômica da Ásia, o Japão passava a adotar discursos que buscavam fortalecer sua identidade asiática - aquela que outrora foi preterida pelo arquipélago no intuito de justificar seu imperialismo desenfreado no continente. Não obstante, também foi o período em que a indústria televisiva japonesa consolidava os trendy dramas - formato de ficção seriada televisiva que foi extensivamente exportado para países do leste e sudeste asiático e, posteriormente, adaptados pelas indústrias locais ${ }^{4}$.

\footnotetext{
${ }^{4}$ Tal formato deu origem a várias emulações por parte dos países vizinhos: TW-Drama (Taiwan), C-Drama (China), HK-Dramas (Hong Kong), K-Drama (Coreia do Sul), dentre outros.
} 
Nesse sentido, as produções japonesas se apresentavam como uma alternativa menos nociva do que os programas estadunidenses.

Diante desse cenário, a entrada do século XXI marca uma nova era para a diplomacia cultural japonesa. A partir de então, o governo diagnosticou que para elevar o seu status no mundo, o Japão precisaria investir mais em seus elementos culturais e tecnológicos. Além disso, a cultura tem cada vez mais sido interpretada como um elemento estratégico para a diplomacia entre as nações. Por diplomacia cultural entendemos um conjunto de práticas governamentais que operam em nome de um ethos bem definido de representação nacional (ANG et al. 2015). Assim, estimula-se a criação de uma imagem nacional específica para atrair as audiências externas, através, por exemplo, da instrumentalização do turismo, da exportação de produtos culturais e midiáticos e da promoção de certos estilos de vida (IWABUCHI, 2015), com o objetivo primário de aprimorar a percepção sobre a imagem de uma certa nação (OTMAZGIN, 2012).

Esse imaginário "repaginado" sobre o Japão ajudou a juventude asiática a desenvolver um senso de cosmopolitismo, estilo de vida e modernidade (ANG, 2010). Isso ocorre por conta de certos valores em comum, que não podem ser dignamente representados através de produções norte-americanas e/ou ocidentais (IWABUCHI, 2002), que não compartilham desse mesmo senso de pertencimento. Para explicar esse fenômeno, Straubhaar (1991) cunhou o termo proximidade cultural. Acentua-se, portanto, a pertinência de certos elementos culturais como vestimentas, gestos e linguagem corporal para se desenvolver certo grau de identificação, bem como a familiaridade étnica. Evidentemente, é pertinente salientar que a proximidade cultural não se dá de forma homogênea, visto os graus de estratificação social e até mesmo por conta de divergências dentro de um mesmo grupo.

Essa boa aceitação da cultura pop e midiática japonesa em outros países ajudou a conduzir uma mudança de posicionamento por parte do governo japonês que, desde 2005, tem oficialmente adotado a agenda de que “o Japão é cool" (Cool Japan) no intuito de promover a sua imagem internacionalmente e desenvolver seu softpower ${ }^{5}$. O ponto-chave da campanha Cool Japan está em “promover a compreensão e confiança do Japão através da utilização da cultura pop e artes tradicionais como suas principais ferramentas para a diplomacia

\footnotetext{
$\overline{{ }^{5} \text { De acordo com Nye }}$ (2005), o soft power representa a capacidade de uma nação em influenciar outras nações por meio de mecanismos culturais e ideológicos. Trata-se de uma estratégia política que visa conquistar a opinião pública, empatia e credibilidade internacional.
} 
cultural" " (tradução nossa). Assim, animês, mangás, culinária japonesa, vestimenta tradicional, moda urbana, turismo, dentre outros, se tornaram ferramentas para obtenção de olhares simpáticos ao Japão. Alguns exemplos que poderiam ser citados das iniciativas promovidas pelo Ministério das Relações Exteriores (Mofa) são os concursos de mangá, campanhas de turismo como a Discover Japan, exibições públicas de animês e a escolha por três jovens japonesas como as embaixadoras da cultura kawaii (fofinha) (MILLER, 2011). Assim, a esfera da cultura se revelou um ambiente possível para "curar as feridas do passado", amansando a imagem negativa vinculada ao Japão. No entanto, mesmo com o boom de popularidade da cultura pop japonesa em diversos países, inclusive nos do leste e sudeste asiático, essas noções precisam ser problematizadas.

A ideia de diplomacia mediada pela cultura pop tende a se sustentar na ideia inocente de que esses produtos de entretenimento são capazes de remediar problemas históricos entre o Japão e outros países asiáticos (IWABUCHI, 2015). No entanto, o consumo do pop japonês por parte de populações asiáticas não anula a necessidade latente das entidades governamentais japonesas adotarem medidas para, de fato, lidarem com questões remanescentes do passado imperialista, como ilustra o caso das mulheres de conforto. Ainda hoje, Japão e Coreia do Sul enfrentam sérios embates para lidar com a questão das mulheres que foram obrigadas a se prostituir e estupradas pelo exército japonês durante a ocupação japonesa na península coreana ${ }^{7}$. No caso chinês, Iwabuchi (2015) observa que embora a camada jovem da população chinesa consuma extensivamente conteúdo pop e midiático japonês, ela continua se demonstrando preocupada e insatisfeita com as relações entre os dois países, também por conta de cicatrizes históricas.

Para o que tange aos interesses do artigo, é essencial ressaltar que o esforço do governo japonês em promover seu conteúdo criativo se tornou majoritariamente ancorado nos animês e mangás e, em menor escala, nos dramas de televisão. Nesse sentido, outros produtos midiáticos - como reality e talk shows - permanecem sendo pouco incentivados diretamente por entidades governamentais japonesas. Ainda assim, esses programas passaram a ser veiculados ao redor do mundo com o apoio de fãs transnacionais e com parcerias realizadas pelo setor privado, como entre a TV Fuji e a Netflix. Com isso, esses programas passaram a circular em diversos países e colaborar com o desenvolvimento de um imaginário sobre o Japão.

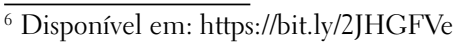

${ }^{7}$ Disponível em: https://glo.bo/36QndOF
} 
Consequentemente, também passaram a funcionar como um instrumento de acúmulo de soft power para o Japão (ARAUJO, 2020). Com isso em mente, direcionamos, a discussão sobre a instrumentalização do soft power japonês a partir do caso de Ainori Love Van.

\section{Reality shows e instrumentalização do soft power japonês: o caso de Ainori Love Van}

Ainori Love Van é um programa de televisão que angariou olhares junto aos públicos globais através de sua nova versão disponibilizada em parceria com a plataforma de filmes e séries Netflix. Embora seja um reality de relacionamento e de apresentação de destinos turísticos, o programa também traz uma reflexão sobre o cotidiano asiático contemporâneo a partir de alguns quadros e, em paralelo, aborda brevemente as diferenças entre os países visitados e o Japão, seja em uma perspectiva positiva ou negativa. Assim, a dinâmica do programa consiste na entrada de sete participantes (três mulheres e quatro homens) em uma van cor de rosa para fazer uma viagem de baixo custo pela Ásia. Sem autorização para utilizar seus celulares, pois devem "focar em se conhecer verdadeiramente", os participantes experienciam uma imersão na cultural local dos países enquanto vão construindo seus relacionamentos. Ao se sentir apaixonado, o participante decide quando declarar os seus sentimentos para a pessoa amada e, se obtiver resposta positiva, os dois voltam juntos para o Japão. Em caso negativo, o participante que se declarou volta sozinho para casa e um novo participante entra em seu lugar.

No entanto, antes mesmo de ganhar a sua edição em parceria com a Netflix, Ainori foi um programa de televisão transmitido entre 1999 e 2009, todas às segundasfeiras, às 23 hs pela TV Fuji. Ao longo de dez anos, o programa conseguiu a marca de passar por 92 países, além de ter formado 44 casais, dentre os quais 8 se casaram. De acordo com a produtora do programa, Mieko Koyama, Ainori, que em sua tradução literal significa "caminhar/amar juntos", tenta criar situações em que os participantes possam realmente se conhecer, através de uma atmosfera e uma cultura diferente, na qual eles tenham a oportunidade de se apaixonar uns pelos outros ${ }^{8}$. Durante esses dez anos de exibição, a média de audiência do reality foi de $15 \%$ e se tornou um verdadeiro fenômeno social no Japão9. Embora Ainori tenha sido finalizado em 2009, no ano seguinte a Fuji TV lançou 10 episódios do programa em Bangladesh, agora sob o título de Ainori 2. Essa versão teve uma maior duração por

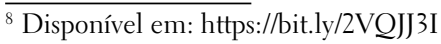

${ }^{9}$ Tradução nossa. Disponível em: https://bit.ly/3ovexTZ
} 
episódio (em torno de 60 minutos) e novas regras sobre limite de tempo em que o participante poderia ficar viajando.

Ainda em 2004, o programa iniciou uma campanha de arrecadação de fundos para ajudar alguns dos países mais pobres que foram visitados, como o Nepal e o Camboja. As doações em dinheiro foram feitas pelos telespectadores e revertidas em atividades educacionais voltadas para as crianças desses países. De acordo com a Fuji TV, as doações ultrapassaram a quantia de 65 milhões de yen, o que seria equivalente a aproximadamente 650 mil dólares americanos ${ }^{10} \mathrm{e}$, com esse valor, foi possível construir sete Ainori Gakkou (escolas do Ainori) ${ }^{11}$ ao redor do mundo. Sem dúvida, iniciativas como esta têm a finalidade de promover o soft power japonês na região e procuram desconstruir a imagem negativa associada ao imperialismo do Japão, uma vez que apontam para uma tentativa de construção de uma faceta mais amigável do país através do intermédio da indústria criativa. Nesse sentido, compreendemos que esse "caráter filantrópico" japonês atua com alguma intenção de remediar as atrocidades cometidas durante o seu período imperialista, a partir de uma apresentação imagética desvinculada desse passado. Desde sua última exibição em 2010, houve um hiatus de oito anos até a nova versão de Ainori ser desenvolvida, dessa vez com a possibilidade de expansão de audiência através de uma parceria firmada entre a Fuji TV com a plataforma de streaming Netflix.

Seguindo a esteira do sucesso de outros programas televisivos oriundos do Japão, os direitos de Ainori foram adquiridos pela Netflix (Figura 1) em 2017, dando origem à versão Ainori: Asian Journey (2017-2019), ainda em parceria com a Fuji TV, a maior emissora privada do Japão e responsável pela criação e distribuição do programa originalmente. Até o presente momento, a referida versão rendeu duas temporadas, exibidas entre 2017 e 2019, com 24 participantes $^{12}$ no total, e passou por 11 países: na primeira temporada, Vietnã, Mianmar, Taiwan (objeto de análise do artigo), Tailândia, Malásia e Singapura e, na segunda, Índia, Nepal, Uzbequistão, Cazaquistão e Quirguistão. A terceira temporada, denominada Ainori:

\footnotetext{
10 Tradução nossa. Disponível em: https://bit.ly/39PLuqb

${ }^{11}$ A iniciativa japonesa para a arrecadação de fundos que são revertidos na construção de escolas em outros países do continente asiático revela que ainda hoje impera certo paternalismo por parte do Japão diante dos demais países do entorno regional, que continuam a ser interpretados com base na utilização de noções de inferioridade e narrativas de atraso. Assim, o Japão adota uma postura de liderança e superioridade civilizatória.

${ }^{12}$ Os participantes da primeira temporada foram Yuchan (homem), Wedding, Hatomune, Taka, Shyboy, Akira, Tom, Sacho, Kanya, Yumechin, Depparin, Asuka, Kasuga e Yuchan (mulher). Na segunda, os participantes Yuchan (mulher), Depparin e Tom retornaram e somaram-se a Mjanma, Dr. Morimori, Isamuchan, Hidekun, A.I., Junki, Mya, Sakurako e Moa.
} 
African Journey (2020), foi ao ar no início de 2020 na Netflix. Essa edição contou com 12 participantes ao todo e quatro países do continente africano foram visitados, a saber: Quênia, Uganda, Ruanda e Tanzânia. Os episódios são comentados por um time de celebridades japonesas, a saber: a personalidade da mídia Becky, a atriz e modelo Mayuko Kawakita, os comediantes Toshiaki Kasuga e Masayasu Wakabayashi e o jovem ator Shimon Okura - que expressam suas opiniões sobre os acontecimentos dos episódios anteriores e fazem especulações sobre o rumo do relacionamento dos participantes.

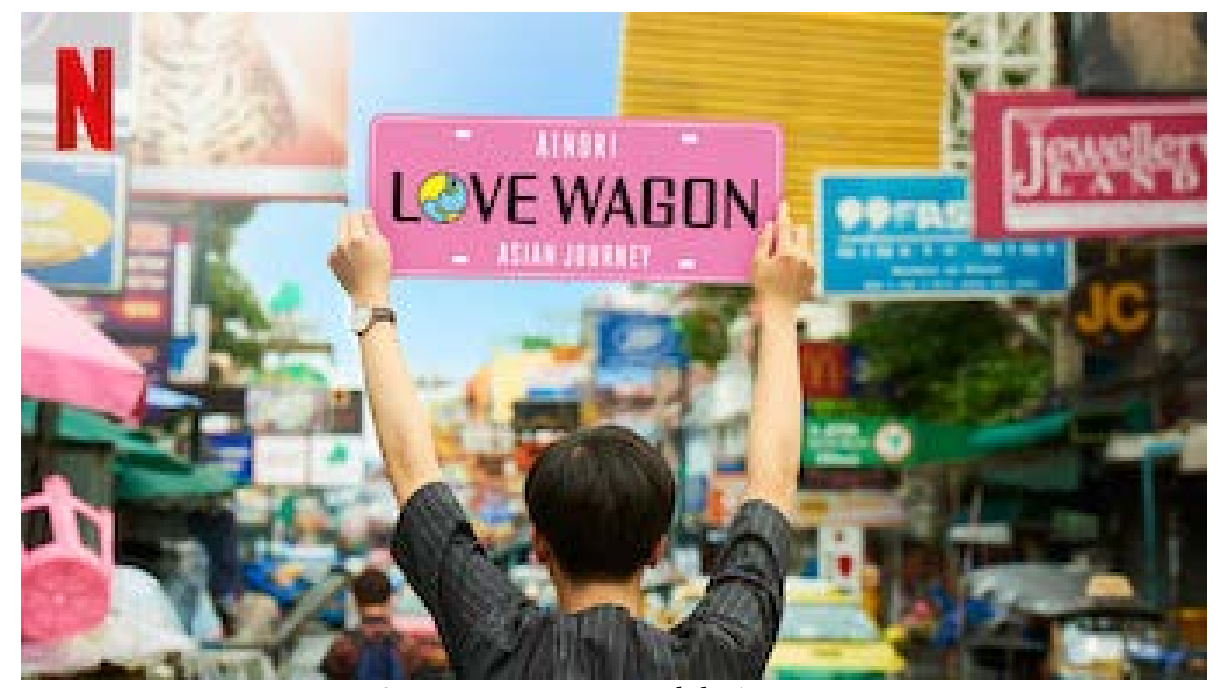

Figura 1: Imagem promocional de Ainori Love Van.

Fonte: Ainori love wagon: asian journey (Fuji Television, 2017).

A partir da inserção de Ainori no catálogo da Netflix, o programa abandonou o seu caráter estritamente doméstico para atingir uma audiência internacional e, com isso, aumenta a possibilidade de difusão desses “novos" discursos sobre o Japão para o restante do mundo. Acentuamos, por sinal, que desde que a campanha Cool Japan foi oficialmente incorporada como ferramenta de promoção do soft power japonês para o restante do mundo, a mensagem que passou a ser vinculada é de que o Japão do século XXI é diferente daquele Japão imperialista do início do século XX. Agora, os seus produtos midiáticos pop procuram traduzir a ideia de que o Japão é um país desejável de ser consumido por audiências locais, regionais e globais.

Por fim, existem blocos chamados "Lições do Ainori" que trazem alguma curiosidade ou informação sobre o país visitado. Nisso apresenta-se um pouco sobre 
a história e a cultura do lugar para a audiência do programa, ao mesmo tempo em que os participantes interagem com a população local através do intermédio do motorista de van, que é sempre um nativo. Dessa forma, os participantes apreendem tais "lições" a partir desse contato com o outro e acabam, com isso, reinterpretando seus próprios olhares sobre seu país de origem. Com isso em mente, separamos o caso da "lição de Ainori" sobre Taiwan para dar corpo à seção seguinte, que traz a análise das mensagens transmitidas pelo programa em diálogo com as noções sobre o imperialismo japonês do início do século XX, bem como a instrumentalização do seu soft power junto aos países vizinhos.

\section{“Lições do Ainori": entre a gentileza de Taiwan e o discurso paternalista japonês}

Como uma colônia do Japão entre 1895 e 1945, Taiwan tem preservado muitos legados culturais japoneses, como a alimentação, linguagem e estilo de vida (HUANG, 2011, p. 7). Os jovens taiwaneses cresceram embalados com as narrativas dos mangás e animês, o que criou as condições de possibilidades para a importação dos dramas de TV japoneses ainda nos 1990. Embora os programas de TV japoneses tenham sido formalmente proibidos em Taiwan depois dos dois países romperam relações diplomáticas em 1972 (ISHII et al., 1999), na década de 1980, esses programas circulavam informalmente em Taiwan através da prevalência de locadoras de vídeos e serviços ilegais de TV a cabo. A proibição de programas japoneses foi suspensa em 1993 e as redes de televisão começaram a transmitir dramas de TV japoneses no horário nobre. A certa altura, seis canais a cabo em Taiwan foram dedicados exclusivamente a programas japoneses. A ênfase dos dramas de TV no elenco e na música também popularizou ídolos e música pop na referida ilha. No final dos anos 90, Taiwan era o maior mercado de exportação de música japonesa, o que ajuda a explicar a dimensão que a cultura pop japonesa adquiriu junto aos públicos de Taiwan (HUANG, 2011), mesmo com a memória histórica vinculada ao processo imperialista japonês na região.

Huang (2011) ainda ressalta que houve momentos em que Taiwan foi criticado por "bajular" o Japão, mas que boicotes à presença cultural japonesa na ilha têm sido raros nos últimos tempos. Um dos motivos que a autora explicita e que ajudam a explicar essa situação reside no fato de que a construção midiática taiwanesa sobre o Japão tem sido cada vez mais positiva, principalmente devido à "mania nacional" que a cultura pop japonesa se tornou sob os olhos da juventude. Em paralelo, é importante ressaltar que Taiwan possui relações complicadas com a China continental e a vitória de Tsai Ing-Wen (PDP) nas eleições presidenciais de 
Taiwan em 2016 e sua reeleição em 2020 acirram ainda mais o caráter conflituoso dessas relações, visto que Ing-Wen sustenta o seu capital político a partir da crítica ao governo de Pequim ${ }^{13}$. Essa atual dinâmica entre Taiwan e China nos levam a crer que na presença de um novo e latente "inimigo", as memórias da colonização japonesa parecem ter ficado distantes e foram substituídas pela iminência de uma suposta "ameaça chinesa”.

Em 11 de março de 2011, um dos maiores terremotos ocorreu na costa noroeste (Tohoku) do Japão. A maior gravidade estava por conta da proximidade da região com a usina nuclear de Fukushima, o que acarretou a declaração de uma emergência nuclear no país. Esse evento causou comoção internacional e diversos países enviaram tropas de resgate e doações em dinheiro para ajudar na reconstrução das áreas atingidas. Dentre essas regiões, Taiwan se destaca por ter sido um dos primeiros vizinhos do Japão a se mobilizarem em prol da reconstrução e ajuda junto aos cidadãos japoneses afetados. De fato, a lição apresentada em Ainori sobre a gentileza de Taiwan no quadro "Lições de Ainori" ${ }^{14}$, revela de maneira bastante contundente a relação ambígua estabelecida entre Japão e Taiwan, enquanto revela o potencial de instrumentalização do soft power da cultura (pop) japonesa junto aos públicos taiwaneses.

"Nós devolvemos o favor", alega uma mulher taiwanesa idosa, dona de uma confeitaria que conversou com os participantes de Ainori, para explicar a exuberante quantia em dinheiro arrecadado em Taiwan para ser enviado ao Japão. O "favor" diz respeito à antiga colonização japonesa na ilha de Taiwan. "Somos todos uma mesma família”, repetia. Nisso, ela explicou para os passageiros que "Taiwan esteve de 1895 a 1945 sob o mesmo governo que o Japão", fato que surpreendentemente os participantes desconheciam. Ela também conta que recebeu a mesma educação que um japonês durante esse período, por conta da "colonização intelectual" (OTMAZGIN, 2012) levada a cabo pelo Japão durante o seu período imperialista. Nesse sentido, a educação recebida pela interlocutora foi moldada ideologicamente para assegurar uma narrativa que reforça o "grande império japonês", justificando a violência praticada pelo Japão na época.

O discurso construído em Ainori sobre a colonização japonesa em Taiwan mascara as atrocidades cometidas pelo governo japonês na época e romantiza o

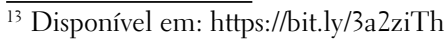

${ }^{14} \mathrm{O}$ caso escolhido para a nossa análise foi retirado do episódio 10 da primeira temporada (T01: EP10) de Ainori Love Van: Asian Journey, denominado “As lanternas no céu”, disponível com legendas em português na Netflix Brasil.
} 
imperialismo. Palavras como "favor", "família” e “amigos" são frequentemente utilizadas para descrever o relacionamento entre as duas nações (Figura 2).

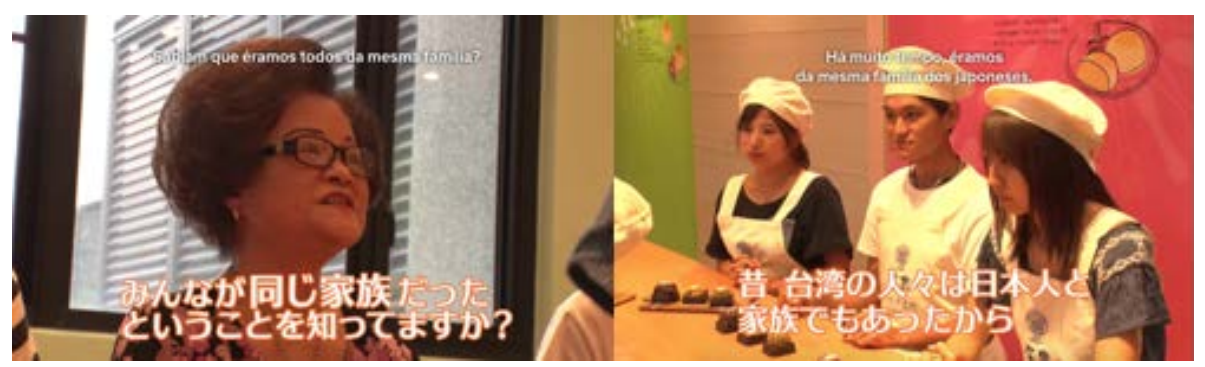

Figura 2: Conversa entre a senhora taiwanesa e os participantes de Ainori Love Van. Fonte: Ainori love wagon: asian journey (Fuji Television, 2017).

O programa também aponta as falhas do governo japonês ao ressaltar que embora Taiwan não tenha poupado esforços para colaborar com o Japão, as entidades governamentais japonesas nunca enviaram notas de agradecimento à Taiwan através de canais oficiais ou notas na mídia, simplesmente porque o Ministério das Relações Exteriores não reconhece Taiwan como um país. Diversos comunicados oficiais de agradecimento foram enviados para países como os Estados Unidos, Inglaterra e Coreia do Sul (que foram descritos como “amigos ao redor do mundo"), mas nenhuma palavra foi proferida a respeito de Taiwan. Isso causou, supostamente, uma indignação nos cidadãos (comuns) japoneses que iniciaram campanhas de arrecadação de dinheiro para financiar a compra de espaço em jornais taiwaneses United Daily News e Liberty Times - demonstrando a sua gratidão.

Mesmo assim, os participantes procuraram a produção do programa e o motorista da van para também demonstrar a gratidão aos taiwaneses pelo dinheiro arrecadado na ocasião de 2011 . Frequentemente eles se diziam "envergonhados" pela falta de consideração do governo nipônico e ressaltavam o quanto o povo taiwanês era gentil com os cidadãos japoneses, apesar dos atos falhos do governo. Assim, os participantes se voluntariaram para trabalhar gratuitamente na construção de uma ponte em uma cidade taiwanesa (Figura 3). Dessa forma, eles poderiam minimizar a displicência diplomática do governo japonês através do agradecimento e boa vontade individuais. 


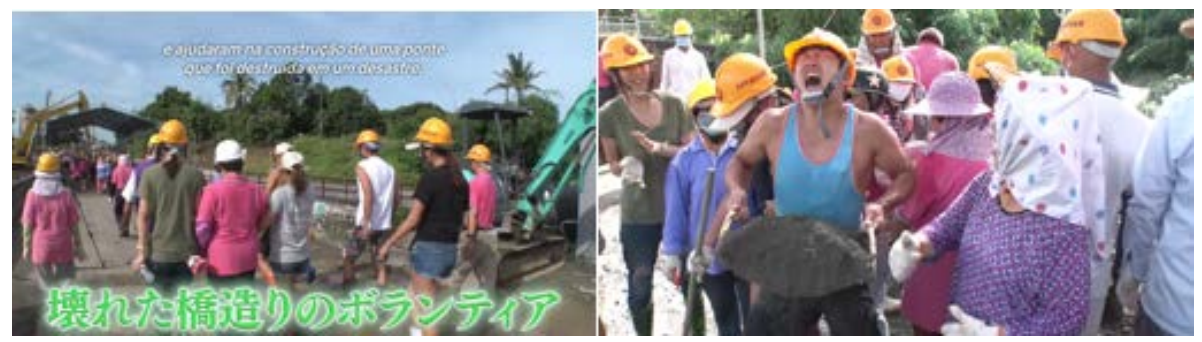

Figura 3: Participantes de Ainori Love Van ajudam na construção da ponte em Taiwan. Fonte: Ainori love wagon: asian journey (Fuji Television, 2017).

O programa busca, portanto, apresentar uma perspectiva positiva acerca dos cidadãos japoneses, representados aqui pelos participantes de Ainori, que se revelaram dispostos a assumir a responsabilidade de retribuir a "gentileza" taiwanesa para com o seu país.

Tendo o discurso construído no referido episódio, percebemos que a relação apresentada entre Japão e Taiwan reflete uma espécie de síndrome de Estocolmo. Em diversos momentos se é pontuado que “os taiwaneses adoram os japoneses" e que, por isso, eles se mostram solícitos nas ruas quando os participantes precisam de ajuda para andar pelas ruas. Ainda que a relação entre Japão e Ásia seja complexa, múltipla e contraditória (IWABUCHI, 2002), a narrativa tenta apagar as problemáticas envolvendo o passado imperialista japonês e, embora critique o governo contemporâneo ao não reconhecer Taiwan como um país, mantém firme a percepção de que os japoneses são melhores do que seu governo e demonstram sua gratidão «com as próprias mãos». Ao mesmo tempo em que Taiwan é apresentado como um país repleto de virtudes, a edição do programa faz questão de ressaltar os "prévios esforços" do Japão em "salvar e civilizar" a ilha. Assim, impera para os espectadores certa noção de que Taiwan possui uma “dívida” com o Japão, devido ao grau do desejável desenvolvimento que foi atingido com o suposto apoio japonês.

Embora seja importante ressaltarmos o enorme esforço realizado na edição do programa em diferenciar os cidadãos “comuns”, isto é, a sociedade civil das entidades governamentais japonesas - uma vez que os participantes são abertos, curiosos, interessados na cultura local e fazem autocrítica -, também precisamos nos atentar para as entrelinhas da narrativa que reafirmam frequentemente a ideia de que o imperialismo japonês foi uma experiência positiva para Taiwan, abrindo mão de qualquer tipo de problematização sobre esse passado. Percebe-se, inclusive, que a "Ásia” retratada por Ainori não é mais um lugar subdesenvolvido e atrasado 
que precisa ser «civilizado» pelo arquipélago. Pelo contrário: trata-se de uma região moderna, vibrante e desenvolvida (IWABUCHI, 2002).

Devido a todos esses fatores, acreditamos que Ainori Love Van procura reforçar o soft power japonês através de uma estratégia de diferenciação, na medida em que reafirma a ideia de que o Japão e, em consequência, sua população, é culturalmente diferenciada do restante da Ásia. Assim, a memória de um passado conturbado pode ser evocada para assegurar o mito de que o Japão trouxe diversos benefícios para a região a partir de suas atitudes imperialistas e, justamente por esta razão, o arquipélago merece apreço.

\section{Considerações finais}

Não é novidade a constatação de que o Japão possui um relacionamento complexo com os países do leste e do sudeste asiático, justamente por conta das ainda vívidas memórias do imperialismo desenfreado que dominou a geopolítica dessa parte da Ásia durante quase a primeira metade inteira do século XX. A colonização de territórios - como foi com Coreia e Taiwan - e a castração da cultura local foi um dos traços mais brutais e característicos dessa relação de dominação. Essa História que não deve ser esquecida continua reverberando até o tempo presente e permanece influenciando as relações entre as nações, principalmente diante de um Japão que tenta varrer a sua responsabilidade sobre esse passado para de baixo dos panos. Para tanto, uma das estratégias utilizadas pelo governo japonês consiste na premissa de transformar a imagem do arquipélago diante do cenário internacional através de medidas que visam estimular o seu soft power (NYE, 2005) e seu nation branding (IWABUCHI, 2015), a fim de vender a narrativa de que o Japão do século XXI é um ator pacífico (ARAUJO; OLIVEIRA, 2020) e cool.

Aqui, utilizamos o caso de Taiwan apresentado na primeira temporada do reality show Ainori: love van, como corpus da análise para refletirmos sobre os discursos que o Japão entoa sobre o seu relacionamento com os países vizinhos atualmente. Nesse sentido, ressaltamos que o programa procura reforçar os laços de amizade e cooperação cultural entre os dois países através de uma narrativa que romantiza o seu próprio passado imperialista. O bloco procura induzir a percepção de que o imperialismo japonês foi benéfico para Taiwan e que o Japão fez um "favor" em assumir o controle do arquipélago. Seguindo essa leitura monolítica, não seria uma surpresa, portanto, que os taiwaneses tratem os japoneses com tanta amabilidade e cortesia - afinal, como a narrativa do episódio afirma em diversos momentos, tanto os taiwaneses quanto os japoneses fazem parte de uma mesma "família". 
Nesta direção, os produtos midiáticos japoneses e a campanha Cool Japan se tornam importantes ferramentas acionadas para difundir outras narrativas sobre o arquipélago. Nesse caso, a tentativa do supracitado reality show é de convencer a audiência - agora internacional - de que o Japão é um país cool e, portanto, amado inclusive na Ásia. Para atingir tal objetivo, Ainori abre mão de apresentar uma veia crítica e respeitosa sobre a memória do passado ao selecionar discursos que didaticamente afirmam que "os fins justificaram os meios". Assim, o programa tenta reescrever o passado ao suavizar as atrocidades cometidas pelo Japão do século passado.

O que se torna evidente é que a narrativa do programa assume o compromisso de apresentar as virtudes do Japão e de sua população, a partir do reforço da mistificação de um Japão imaginado. Com isso, traduz de maneira explícita o quanto o país ainda tem que se esforçar para melhorar verdadeiramente o seu relacionamento com os demais países asiáticos. Tarefa que depende muito mais de posturas de seus representantes políticos do que de sua cultura midiática pop.

\section{Referências bibliográficas}

ALBUQUERQUE, A.; CORTEZ, K. "Cultura pop e política na nova ordem global: lições do extremo oriente”. In: CARREIRO, R.; FERRARAZ, R.; SÁ, S. (org). Cultura Pop. Salvador, BA: Edufba, 2015. p. 247-267.

ANG, I. "The cultural intimacy of TV drama”. In: IWABUCHI, K (org.). Feeling asian modernities: transitional consumption of TV dramas. Hong Kong: Hong Kong University Press, 2004. p. 303-310.

ANG, I.; ISAR, R. Y.; MAR, P. "Cultural diplomacy: beyond the national interest?”. International Journal of Cultural Policy, Abingdon, v. 21, n. 4, p. 365-381, 2015.

ARAUJO, M. "Além do animê: reality TV e o soft power japonês”. Revista Fronteiras, São Leopoldo, v. 22, n. 2, p. 103-113, 2020.

ARAUJO, M.; OLIVEIRA, A. "Construindo o amanhã: o pop japonês como recurso de soft power para a imagem do Japão nas olimpíadas de 2021”. Revista Compolítica, Rio de Janeiro, v. 10, n. 3, 2020. 163-188.

HUANG, S. "Nation-Branding and transnational consumption: Japan-mania and the Korean Wave in Taiwan”. Media, Culture \& Society, v. 33, n. 1, 2011.

HUNG, H. "A ascensão da China, a Ásia e o Sul global”. Revista de economia contemporânea, Rio de Janeiro, v. 22, n. 1, 2018. p. 1-26. 
HUFFMAN, J. Japan and Imperialism (1853-1945). Michigan: Association for Asian Studies Publisher, 2010.

ISHII, K.; SU, H.; WATANABE, S. "Japanese and US programs in Taiwan: new patterns in taiwanese television". Journal of Broadcasting 6 Electronic Media, London, v. 43, n. 3, 1999. p. 416-431.

IWABUCHI, K. Recentering globalization. North Carolina: Duke University Press, 2002.

IWABUCHI, K. "Cultural globalization and asian media connections". In: Feeling Asian Modernities. Hong Kong: Hong Kong University Press, 2004. p. 1-22.

IWABUCHI, K. "Pop-culture diplomacy in Japan: soft-power, nation branding and the question of "international cultural exchange". International Journal of Cultural Policy, Abingdon, v. 21, n. 4, p. 419-432, 2015.

JOO, J. “Transnationalization of korean popular culture and the rise of "pop nationalism” in Korea”. The Journal of Popular Culture, Hoboken, v. 44, n. 3, 2011. p. 489-504.

MATSUDA, H. "Japanese "new imperial history" in comparative perspective the cases of okinawan and taiwanese migrations". Journal of History for the Public, Viena, v. 13, 2016.

MILLER, L. “Taking girls seriously in ‘cool Japan' ideology”. In: HEINE, S. (ed.). Japan studies review. Florida: Florida International University, p. 97-106, 2011.

NYE, J. Soft power: the means to success in world politics. New York: Public Affairs, 2005.

ORTIZ, R. O próximo e o distante: Japão e modernidade-mundo. São Paulo: Brasiliense, 2000.

OTMAZGIN, N. "Popular culture and regionalization in east and southeast Asia". In: OTMAZGIN, N.; BEN-ARI, E. (org.). Popular Culture Co-Productions and Collaborations in East and Southeast Asia, 2007. Kyoto: NUS Press, p. 499-523.

OTMAZGIN, N. “Geopolitics and soft power: Japan's cultural policy and cultural diplomacy in Asia”. Asia-Pacific Review, Abingdon, v. 19, n. 1, 2012. p. 37-61.

STRAUBHAAR, J. "Beyond media imperialism: asymmetrical interdependence and cultural proximity". Critical Studies in Mass Communication, Abingdon, v. 8, n. 1, 1991. p. 39-59. 
SUZUKI, K. The State and racialization: the case of koreans in Japan. San Diego: The Center for Comparative Immigration Studies (CCIS): University of California, 2003.

YAMATO, E. "Construction of discursive fandom and structural fandom through anime comics and game fan conventions in Malaysia”. European Journal of Cultural Studies, Newbury park, v. 21, n. 4, 2016. p. 1-17.

submetido em: 17 dez. 2019 | aprovado em 5 out. 2020 